\title{
CREEP BUCKLING OF ICE SHELVES AND THE FORMATION OF PRESSURE ROLLERS
}

\author{
By I. F. COLLINS and I. R. MCCRAE
}

(Department of Theoretical and Applied Mechanics, University of Auckland, Auckland, New Zealand)

ABSTRACT. Much of the surface of an ice shelf is covered with series of undulations. These undulations or "pressure rollers" are particularly noticeable in the neighbourhood of ice rises or ice streams. To date, there is no satisfactory theoretical model explaining the formation of these waves. As a contribution to understanding this phenomenon, this paper investigates the stability of ice shelves to perturbations in the background stress and strain-rate distributions.

The perturbation analysis is based on Glen's creep law and leads to a continuous eigenvalue problem for the wavelength of the disturbance as a function of growth-rate. It is shown that, provided these strain-rates are sufficiently compressive, waves of the type observed can be expected to form. It is shown that lateral extensional strain-rates have a destabilizing effect and pressure rollers are more likely to form when these are present. Comparison of predicted wavelengths is made with available field data.

RÉsumé. Flambage des shelfs et développément des vagues de pression. La surface des shelfs est en grande partie couverte d'ondulations. Celles-ci, encore appelées "vagues de pression", sont particulièrement développées au voisinage des domes ou des courants de glace. On ne dispose pas actuellement de modèle théorique expliquant ces ondulations de manière satisfaisante. Pour mieux comprendre ce phénomène, nous étudions la stabilité des shelfs aux perturbations des champs moyens de contraintes et de vitesses de dèformation.

L'analyse des perturbations est basée sur la loi de fluage de Glen; elle conduit à un problème aux valeurs

\section{INTRODUCTION}

Series of undulations or depressions of ten called "pressure ridges", "pressure rollers", "ice rumples", or "folds" are common features of ice shelves. This phenomenon is particularly noticeable up-stream from ice rises where the shelf runs aground, and in other regions where the ice is moving close to land, on the edges of ice streams flowing into the main body of a shelf and at a shelf's seaward edge. In his review of ice shelves, Thomas (1979) commented that, whilst the surface of an ice shelf appears completely flat, detailed measurements show that it is in fact undulated with wavelengths of $1-10 \mathrm{~km}$ and wave heights of up to $5 \mathrm{~m}$. Swithinbank (1957) also mentioned a similar subdued wave system with amplitudes of $3-5 \mathrm{~m}$ and wavelengths of about $4 \mathrm{~km}$ on the Maudheim Is-shelf.

Often, in regions where the larger waves form, such as near an ice rise, there are significant stresses in the ice in addition to those caused by the shelf creeping under its own weight. However, this is not obviously so for the waves observed at the seaward edge of a shelf. Robin (1979) has suggested that in this case these undulations are probably caused by the ice flow diverging laterally as it approaches the sea, because the ice shelf is no longer restricted by the confines of the bay. This lateral flow produces large extensional strain-rates parallel to the ice front which causes the waves to form by a type of "necking" process. propres continu pour la longueur d'onde de la perturbation en fonction de la vitesse de croissance. On montre que si les vitesses de déformation sont suffisamment compressives, on peut s'attendre à voir apparaître des ondulations comparables à celles que l'on observe. On montre également que les extensions latérales ont un effet déstabilisateur et que les vagues de pression ont plus de chance de se former lorsqu'elles existent. Les longueurs d'onde prévues sont comparées aux données de terrain existantes.

ZUSAMMENFASSUNG. Kriech-Aufwölbungen von Schelfeisen und die Bildung von Druckwalzen. Ein Grossteil der Oberfläche von Schelfeisen ist mit Serien von Undulationen bedeckt. Diese Undulationen oder "Druckwalzen" treten vor allem in der Umgebung von Eisaufwölbungen oder Eisströmen auf. Bis heute gibt es noch kein befriedigendes theoretisches Modell, das die Bildung dieser Wellen erklären könnte. Als Beitrag für das Verständnis des Phänomens untersucht diese Arbeit die Stabilităt von Schelfeisen gegenüber Störungen in der Hintergrundsspannung und in der Verteilung der Verformungen.

Die Analyse der Störungen beruht auf dem Glen'schen Fliessgesetz und führt auf ein kontinuierliches Eigenwertproblem für die Wellenlänge der Störung als Funktion der Wachstumsrate. Es wird gezeigt, dass bei ausreichend kompressiven Verformungen die Bildung von Wellen des beobachteten Typs erwartet werden kann. Weiter zeigt sich, dass seitliche Dehnungsverformungen eine destabilisierende Wirkung haben und dass Druckwalzen sich bei deren Anwensenheit eher bilden. Die vorausberechneten Wellenlängen werden mit verfügbaren Felddaten verglichen.

The wavelengths and amplitudes of the pressure rollers can vary considerably. Near Scott Base, the McMurdo Ice Shelf is forced against Ross Island (Fig. 1) and the undulations, when forming, have wavelengths of $91 \pm 2 \mathrm{~m}$. They grow to amplitudes of $3 \mathrm{~m}$ and reduced wavelengths of $35 \mathrm{~m}$ due to the compressive strain-rates, before splitting of the crests and overthrusting occurs (Holdsworth and Heine, 1979).

Several parties travelling in Antarctica have reported encountering pressure rollers caused by ice streams thrusting into ice shelves. These have been summarized by Swithinbank (1957). Sightings were reported by Wright and Priestley (1922) 50 miles $[80.5 \mathrm{~km}$ ] from the mouth of Beardmore Glacier of waves approaching $40 \mathrm{ft}[12.2 \mathrm{~m}]$ in height with a wavelength of some 2 miles [3.2 km]. Gould (1935) and Wild, writing in Mawson (1915), referred to undulations on the Shackleton Ice Shelf as having a wavelength of $3 / 4$ mile $[1.2 \mathrm{~km}]$ and an amplitude of $30 \mathrm{ft}$ [9.1 m]. Undulations on the seaward margin of the ice shelves of west Dronning Maud Land, with wavelengths of $1 \mathrm{~km}$ and amplitudes of $10 \mathrm{~m}$ have been reported by Swithinbank (1957). Kehle (1964) described a detailed study of the vicinity of Camp Michigan near the front of the Ross Ice Shelf. The pressure rollers in this area have amplitudes of $12-15 \mathrm{~m}$ and wavelengths of $180-650 \mathrm{~m}$.

The orientation of the ridges of the rollers relative to the flow direction can vary significantly. At Pram Point, the velocity vectors are at $10-20^{\circ}$ to the principal direction 


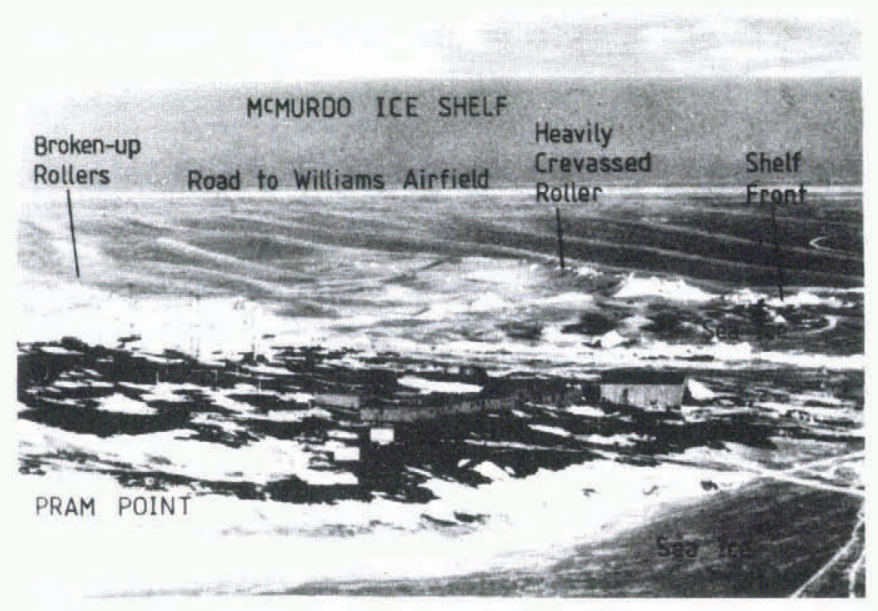

Fig. 1. Pressure rollers at Pram Point near Scott Base, Antarctica.

of maximum compressive strain-rate, which is normal to the axes of the ridges. Where the rollers are formed by a pure shearing action, the ridges are aligned at approximately $45^{\circ}$ to the flow direction (Thomas, 1979).

Previous attemnts to model the formation of rollers have assumed that the buckling of the shelf is either an elastic phenomenon as in Hochstein (1967) or Hughes (1983), or a linearly visco-elastic effect as in the analysis of Kehle (1964). However, in view of the time-scale of the formation process, it would seem more likely that the formation of these rollers is a consequence of creep instabilities of the type familiar in metals at elevated temperatures (Odqvist, 1966) and which will be governed by the well-known power creep law of ice, i.e. Glen's law. In his analysis, Hochstein (1967) showed that the force needed to produce elastic buckling was $10^{3}$ times larger than that which caused significant plastic (creep) flow and hence concluded that the buckling could not be an elastic phenomenon.

In this paper we study theoretically the growth of wave-like instabilities in an idealized ice shelf. Initially, the base solution will be taken to be that given by Weertman (1957) for a parallel-faced ice shelf deforming under planestrain conditions. The influence of lateral straining analysed by Thomas (1973) is discussed in a later section. We imagine the waves to form as a result of the presence of some small superposed stresses. The precise cause of these perturbation stresses is not modelled but they could well be due to the presence of ice rises or of infiltrating ice streams.

The mathematical model used is similar to that which has been used to study the formation of folds in the rock strata in the Earth's crust. The similarity between the folding of rock layers and ice shelves was emphasized by Kehle (1964). A number of studies of buckling instabilities based on power-law creep models of layered rocks have been made by Fletcher (1974), Smith (1975, 1977, 1979), and Neurath and Smith (1982). The particular mathematical procedure used in this paper is similar to that used by Smith (1977) to analyse the creep buckling of a rock layer embedded between two less-competent, semi-infinite layers, when subjected to longitudinal compression.

As will be seen, the wavelength of the instabilities is a continuous function of the growth-rate and we shall assume that the waves which will actually form will be those possessing the maximum growth-rate. This hypothesis is due to Biot (1965), though with reference to linear visco-elastic instabilities.

MATHEMATICAL MODEL OF CREEP BUCKLING OF ICE SHELVES

\section{Constitutive equations}

We shall write Glen's law in the form

$$
\sigma_{i j}^{\prime}=\mu(\theta) e_{i j}
$$

where $\sigma^{\prime} i j=\sigma_{i j}+p \delta_{i j}$ is the deviatoric stress tensor formed by subtracting the mean normal (hydrostatic) pressure $p \delta_{i j}$ from the actual stress terisor $\sigma_{i j}$, and $e_{i j}$ is the strain-rate tensor. The generalized viscosity $\mu$ is a function of $\theta$, the second strain-rate invariant defined by

$$
\theta^{2}=\frac{1}{2} e_{i j} e_{i j}
$$

$\theta$ is related to $\tau$, the second invariant of the deviatoric stress, defined by

$$
\tau^{2}=\frac{1}{2} \sigma_{i j}^{\prime} \sigma_{i j}^{\prime},
$$

by the power-law relation

$$
\theta=(\tau / B)^{n}
$$

where the power $n$ is a constant $\approx 3$, whilst $B$ is a function of temperature. It follows from Equations (1) to (4) that the viscosity function is given by

$$
\mu=B \theta^{(1-n) / n} \text {. }
$$

When $n>1$, the power law represents a strain-rate softening material and so $\mu$ is a decreasing function of $\theta$. Estimated values of $B$, averaged through the ice thickness, have recently been given by Thomas and MacAyeal (1982) for the Ross Ice Shelf.

\section{The zeroth-order solution}

Weertman's (1957) analysis assumes an ice shelf of constant thickness $h$, with parallel top and bottom surfaces, deforming under plane-strain conditions. The bottom surface is at a depth $\rho_{\mathrm{i}} h / \rho_{\mathrm{w}}$ below mean sea-level where $\rho_{\mathrm{i}}$ and $\rho_{w}$ are the (mean) densities of ice and sea-water, respectively. Weertman demonstrated the existence of a simple steady-state solution in which the strain-rate components are uniform. This is going to be our zeroth-order solution about which we will consider small perturbations. With the notation of Figure 2, the zeroth-order strain-rates

$$
e_{x x}^{(0)}=K, e_{y y}^{(0)}=0, e_{z z}^{(0)}=-K .
$$

The constant creep-rate $K$ is positive if the ice shelf is extending and negative if it is compressing in the flow direction. The zeroth-order strain-rate invariant $\theta^{(0)}=|K|$. The plane-strain assumption requires $\sigma_{y y}(0)=\left(\sigma_{x x}(0)+\right.$ $\left.\sigma_{z z}{ }^{(0)}\right) / 2$ from Equation (1), so that the zeroth-order stress invariant $\tau^{0}=\frac{1}{2}\left|\sigma_{x x}(0)-\sigma_{z z}(0)\right|$.

Thus from Equations (4) and (5)

$$
\left|\sigma_{x x}{ }^{(0)}-\sigma_{z z}{ }^{(0)}\right|=2 B|K|^{1 / n}=2 \mu_{0}|K| .
$$

Since the $x-, y$-, and $z$-directions are principal stress directions,

$$
\sigma_{x z}{ }^{(0)}=\sigma_{y z}{ }^{(0)}=\sigma_{x y}(0)=0
$$

and the equilibrium equations reduce to

$$
\sigma_{x x, x}^{(0)}=0 \text { and } \sigma_{z z, z}^{(0)}+\rho_{\mathrm{i}} g=0 .
$$

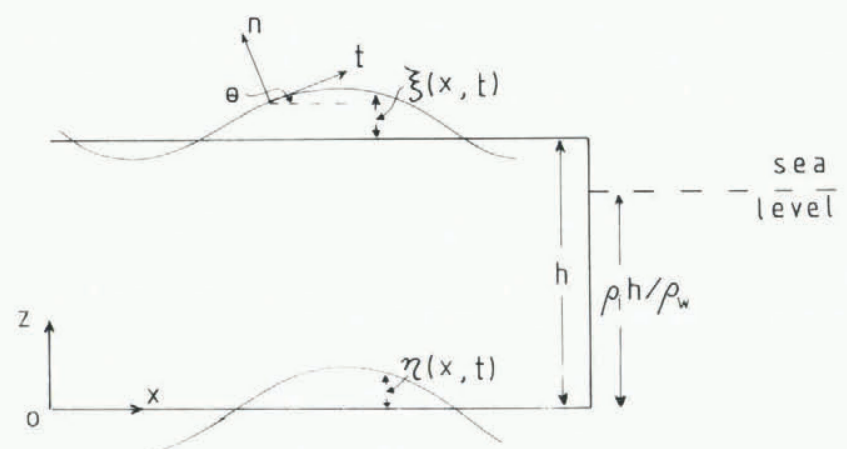

Fig. 2. Notation. 
Solving Equations (7) and (8) and using the stress-boundary conditions on the upper $\left(\sigma_{z z}(0)(h)=0\right)$ and lower $\left(\sigma_{z z}(0)(0)\right.$ $\left.=-\rho_{\mathrm{i}} g h\right)$ surfaces, gives

$$
\begin{aligned}
& \sigma_{x x}(0)=2 \mu_{0} K-\rho_{\mathrm{i}} g(h-z), \\
& \sigma_{z z}(0)=-\rho_{\mathrm{i}} g(h-z) .
\end{aligned}
$$

This solution will be assumed to describe the local background stress and strain-rate states in the ice shelf. The resultant compressive force acting through the shelf is

$$
-\int_{0}^{h} \sigma_{x x}{ }^{(0)} \mathrm{d} z=-2 \mu_{0} K h+\frac{1}{2} \rho_{\mathrm{i}} g h^{2} .
$$

Weertman equated this to the total force of the sea-water on the ice front, i.e. to $\rho_{1}^{2} g h^{2} / 2 \rho_{\omega}$, and so obtained an expression for the creep-rate $K$. However, here we will follow Thomas (1979) and allow for the addition of a "back pressure" $P$ which arises from the resistance of ice rises and the shelf margins. So from Equation (10) the creep-rate $K$ is given by

$$
\operatorname{sign}(K) K^{1 / n}=\left(\rho_{\mathrm{i}} \Delta \rho g h-2 P\right) / 4 B
$$

where $\Delta \rho=\left(1-\rho_{i} / \rho_{\omega}\right)$. When $P=0, K$ is positive and the shelf is extending; compressive flows will occur however when the back pressure exceeds $\frac{1}{2} \rho_{j} \Delta \rho g h$. Thomas and MacAyeal (1982) have plotted contours of the resisting force $F=P h$ on the Ross Ice Shelf obtained from the RIGGS data.

\section{Perturbation equations}

The stress and strain-rate fields in the buckled ice shelf will be regarded as the sum of the above zeroth-order solution together with perturbed fields denoted by $\tilde{\sigma}_{i j}$ and $e_{i j}$. The viscosity function is hence

$$
\mu\left(\theta^{(0)}+\tilde{\theta}\right)=\mu_{0}+\mu_{0}^{\prime} \tilde{\theta}+0\left(\tilde{\theta}^{2}\right)
$$

where $\mu_{0}^{\prime}$ stands for $d \mu / d \theta$ evaluated at $\theta=\theta^{(0)}$, which from Equation (5) is given by

$$
=-\left(1-\frac{1}{n}\right) \mu_{0} / \theta^{(0)} \text {. }
$$

The first-order perturbed stress and strain-rate fields are related by

$$
\tilde{\sigma}_{i j}^{\prime}=\mu_{0} \tilde{e}_{i j}+\mu_{0} e_{i j}{ }^{(0)} \tilde{\theta}
$$

using Equations (1) and (12). The perturbation in the second strain-rate invariant is

$$
\tilde{\theta}=\tilde{e}_{k l}\left(\partial \theta / \partial e_{k l}\right)^{(0)}
$$

using the standard Taylor series expansion; but

$$
2 \theta^{(0)}\left(\partial \theta / \partial e_{k l}\right)^{(0)}=e_{k l}^{(0)}
$$

obtained by differentiating Equation (2), so that

$$
\tilde{\theta}=\tilde{e}_{k l}{ }^{(0)} \tilde{e}_{k l} / 2 \theta^{(0)} \text {. }
$$

In the zeroth-order solution all the strain-rate components are zero except for $\widetilde{e}_{x x}(0)=-\widetilde{e}_{z z}(0)=K$ and in the perturbed solution $\widetilde{e}_{x x}=-\widetilde{e}_{z z}$, since the deformation is still assumed plane strain, so that Equation (15) can be rewritten

$$
\tilde{\theta}=\operatorname{sign}(K) \tilde{e}_{x x}=-\operatorname{sign}(K) \tilde{e}_{z z} .
$$

Finally, substituting from Equations (13) and (15') into Equation (14) gives the perturbed stresses as

$$
\begin{aligned}
& \tilde{\sigma}_{x x}=-\tilde{p}+\left(\mu_{0} / n\right) \tilde{e}_{x x}, \\
& \tilde{\sigma}_{z z}=-\tilde{p}+\left(\mu_{0} / n\right) \tilde{e}_{z z}, \\
& \tilde{\sigma}_{x z}=\mu_{0} \tilde{e}_{x z}
\end{aligned}
$$

where $\tilde{p}$ is the value of the hydrostatic stress in the perturbed stress field.

The "shear viscosity" relative to the $x, z$-axes is hence $\mu_{0}$, the value in the background state, but the "extensional viscosity" is reduced to $\mu_{0} / n$ due to the pure compression/extension in the $x, z$-directions in the ground state. The ice will hence offer less resistance to further extension or compression in the horizontal and vertical directions than it will to shearing in the vertical plane. This kind of "stress-induced anisotropy" is of course a characteristic feature of non-linear materials.

Since the perturbed deformation is isochoric, we can introduce a stream function $\psi(x, z)$ such that the velocity components are $(\tilde{u}, \tilde{w})$ where

$$
\tilde{u}=\psi, z \text { and } \tilde{w}=-\psi, x .
$$

The strain-rate components are found by differentiation and when substituted in Equations (16) gives the stress components

$$
\begin{aligned}
& \tilde{\sigma}_{x x}=-\tilde{p}+\left(\mu_{0} / n\right) \psi_{x z}, \\
& \tilde{\sigma}_{z z}=-\tilde{p}-\left(\mu_{0} / n\right) \psi_{x z}, \\
& \tilde{\sigma}_{x z}=\left(\mu_{0} / 2\right)\left(\Psi_{z z}-\psi_{x x}\right) .
\end{aligned}
$$

Substituting these expressions in the perturbed equilibrium equations

$$
\tilde{\sigma}_{x x, x}+\tilde{\sigma}_{x z}, z=\tilde{\sigma}_{x z, x}+\tilde{\sigma}_{z z, z}=0
$$

yields the following expressions for the pressure gradients

$$
\begin{aligned}
& \tilde{p}_{x}=\mu_{0}\left(\frac{1}{n}-\frac{1}{2}\right] \Psi, x x z+\frac{1}{2} \mu_{0} \psi_{z z z}, \\
& \tilde{p}_{y_{z}}=-\mu_{0}\left(\frac{1}{n}-\frac{1}{2}\right) \psi_{x z z}-\frac{1}{2} \mu_{0} \psi_{x x x} .
\end{aligned}
$$

Finally, eliminating $p$ gives the fourth-order equation

$$
\psi_{x x x x}+2\left[\frac{2}{n}-1\right] \Psi_{x x z z}+\psi_{z z z z}=0
$$

for the stream function $\psi$. This is the anisotropic biharmonic equation which governs the plane-response behaviour of anisotropic elastic solids (see Biot, 1965). It reduces to the ordinary bihaımonic equation $\nabla^{2}\left(\nabla^{2} \psi\right)=0$ for a Newtonian viscous model with $n=1$.

\section{Boundary conditions}

The perturbed shape and motion of the sheif will be obtained by solving Equation (21), subject to suitable boundary conditions on the upper and lower surfaces, which we shall denote by $z=h+\xi(x, t)$ and $z=\eta(x, t)$ respectively (Fig. 2), where $|\xi|,|\eta| \ll h$.

The normal and shear-traction components on the upper surface are zero, so choosing local normal and tangential coordinates (Fig. 2)

$$
\sigma_{n n}=\sigma_{n t}=0 \text {. }
$$

The $x, z$ stress components can be obtained by the usual rules for the rotation of stress components and can be written in terms of the only non-zero local direct stress $\sigma_{t i}$ :

$\sigma_{x x}=\sigma_{t t} \cos ^{2} \theta, \sigma_{z z}=\sigma_{t t} \sin ^{2} \theta, \sigma_{x z}=\frac{1}{2} \sigma_{t t} \sin 2 \theta$

where $\theta=\xi, x$ is the surface slope. Working to first order in $\theta$, we see that

$$
\sigma_{z z}=0 \text { and } \sigma_{x z}=\sigma_{x x^{\theta}}
$$

Applying the first of these conditions $\sigma_{z z}(0)+\tilde{\sigma}_{z z}=0$ on the deforming surface $z=h+\xi$ and using the Equations (9) for $\sigma_{z z}{ }^{(0)}$, we obtain the boundary condition

$$
\tilde{\sigma}_{z z}=-\rho_{\mathrm{i}} g \xi .
$$


Similarly, the second condition in Equations (23') gives the boundary condition in the shear stress

$$
\tilde{\sigma}_{x z}=2 \mu_{0} K \xi, x .
$$

These conditions can be put in terms of the stream function $\psi$ by using Equations (18)

and

$$
\begin{gathered}
\tilde{p}+\left(\mu_{0} / n\right) \psi, x z=\rho_{\mathrm{i}} g \xi \\
\left(\psi_{z z}-\psi, x x\right)=4 K \xi, x .
\end{gathered}
$$

Differentiating Equation (24') with respect to $x$, eliminating $p, x$ from the equilibrium Equation (20), and finally eliminating $\xi, x$ from Equation (25') gives one boundary condition on $\psi$ on the upper surface, $z=h$ :

$$
(1 / h \sigma)\left(\psi_{z z}-\psi_{x x}\right)+\left(1-\frac{4}{n}\right) \psi_{x x z}-\psi_{z z z}=0
$$

where $\sigma$ is the dimensionless stress coefficient defined by

$$
\sigma=\frac{2 \mu_{0} K}{\rho_{\mathrm{i}} g h}=\frac{2 \mathrm{~B} \operatorname{sign}(K)|K|^{\frac{1}{n}}}{\rho_{\mathrm{i}} g h} .
$$

An analogous argument can be used to find a boundary condition on the lower surface. The presence of the sea-water pressure means that Equation (24) is replaced by $\tilde{\sigma}_{z z}=\left(\rho_{\mathrm{w}}-\rho_{\mathrm{i}}\right) g \eta$. The rest of the derivation goes through similarly and Equation (26) is replaced by

$$
\begin{array}{r}
-(\Delta \rho / h \sigma(1-\Delta \rho))\left(\Psi_{,_{z z}}-\psi_{, x x}\right)+ \\
+\left(1-\frac{4}{n}\right) \psi_{, x x z}-\Psi_{z z z}=0 \text { on } z=0
\end{array}
$$

where $\Delta \rho=\left(1-\rho_{\mathrm{i}} \rho_{\mathrm{w}}\right)$.

The remaining two boundary conditions come from the usual kinematic condition in linear wave problems, namely, that the rate of change of surface elevation is equal to the vertical velocity component on each surface, i.e.

$$
w=-\psi_{x_{x}}=\left\{\begin{array}{l}
\xi_{t} \text { on } z=h \\
\eta_{t} \text { on } z=0
\end{array}\right\} .
$$

Following Biot (1965) and Smith (1977), we now look for disturbances which are growing exponentially with a growth-rate $G$. So that

$$
\xi(x, t)=f(x) \exp (G t) \text { and } \eta(x, t)=g(x) \exp (G t)
$$

where $f$ and $g$ are amplitude functions, and

$$
\xi_{, t}=G \xi \text { and } \eta_{t}=G \boldsymbol{\eta}
$$

so that the kinematic conditions in Equation (30) become

$$
\psi_{x}+G \xi=0 \text { on } z=h \text { and } \psi_{x}+G \eta=0 \text { on } z=0
$$

Finally, differentiating these expressions with respect to $x$ and eliminating $\xi$ or $n$ from Equations (25'), we obtain the remaining two boundary conditions on $\psi$

$$
(1-4 K / G)_{,_{x x}}=\psi_{z z} \text { on } z=0 \text { and } z=h \text {. }
$$

We thus have a determinate problem for the perturbed motion: to solve the anisotropic biharmonic Equation (21) for $\psi$ subject to boundary conditions in Equations (26), (28), and (33).

\section{Wave solutions}

We now seek solutions to this system of equations in the form of a uniform train of waves with wave number $k$, so that $\xi, \eta, \psi$, and all the other perturbation variables vary with $x$ as $\exp (i k x)$. In particular,

$$
\psi(x, z)=\Theta(z) \exp (i k x) .
$$

We assume $k$ is real so that the wave train is not damped. In effect we are solving the problem for an infinitely long shelf. Substituting Equation (34) into the governing Equation (21) gives a linear fourth-order ordinary differential equation for $\Phi(z)$ with solutions of the form $\exp (v k z)$ where $v$ satisfies the quartic equation

$$
v^{4}-2 \omega v^{2}+1=0
$$

where $\omega=(2-n) n$, so that $v$ takes one of the four values $v_{j}, j=1,2,3,4$;

$$
v_{j}= \pm\left(\omega \pm\left(\omega^{2}-1\right)^{\frac{1}{2}}\right)^{\frac{1}{2}} .
$$

For $n<1$, these roots are all real and distinct, for $n=1$ there are two repeated roots $( \pm 1)$ and for $n>1$ there are two sets of complex conjugate roots. In the limit as $n \rightarrow \infty$, corresponding to a perfectly plastic material, Equation (36) has two repeated pure imaginary roots $( \pm 1)$. For ice with $n$ $\approx 3$ the variation of $\psi$ through the shelf thickness is hence the sum of four damped oscillations.

$$
\psi(x, z)=\exp (i k x) \sum_{j=1}^{4} a_{j} \exp \left(k v_{j} z\right) .
$$

\section{Determination of wavelengths}

Substituting Equation (37) into the four boundary conditions in Equations (26), (28), nd (33) yields a set of four linear homogeneous equations for the vector $a$ of coefficients $a_{j}$ of the form

$$
B a=0
$$

where the elements of the rows of the $(4 \times 4)$ matrix $B$ are

$$
\left.\begin{array}{l}
\left((G / K)\left(1+v_{j}^{2}\right)-4\right) \\
\left((G / K)\left(1+v_{j}^{2}\right)-4\right) \exp \left(h k v_{j}\right) \\
\left(\left(1-\sigma h k v_{j}\right)\left(1+v_{j}^{2}\right)+4 \sigma h k v_{j} / n\right) \exp \left(h k v_{j}\right) \\
\left(-\left(\left(\Delta \rho /(1-\Delta \rho)+\sigma h k v_{j}\right)\left(1+v_{j}^{2}\right)+4 \sigma k h v_{j} / n\right)\right.
\end{array}\right\}
$$

for $j=1,2,3,4$.

The ice shelf can buckle and waves form if Equation (38) has a non-zero solution for $a$, i.e. if $B$ is singular and

$$
\operatorname{det} B=0 \text {. }
$$

This can be regarded as an equation determining the nondimensional growth rate $y=G /|K|$ as a function of

(i) dimensionless wavelength $\lambda=2 \pi / k h$,

(ii) stress coefficient $\sigma=2 \mu_{0} K / \rho_{\mathrm{i}} g h$,

(iii) density ratio $\Delta \rho=\left(1-\rho_{\mathrm{i}} / \rho_{\mathrm{W}}\right)$

(iv) the creep-law index $n$,

i.e. $\quad y=f(\lambda, \sigma, \Delta p, n)$.

Equation (40) is quadratic in $(G / K)$, so that the equation could be constructed by evaluating det $B$ (which is always real) for three different growth-rates and then solved analytically. It was found that the roots for $y$ were always real and either both negative or with one root negative and the other positive. A negative growth-rate implies that the disturbance dies away and the ice shelf is stable. We are herfe principally concerned with the positive growth-rate solution.

\section{Critical stress regimes}

The variation of growth-rate with stress coefficient for various wavelengths is illustrated in Figure 3. Three separate regimes can be distinguished. 


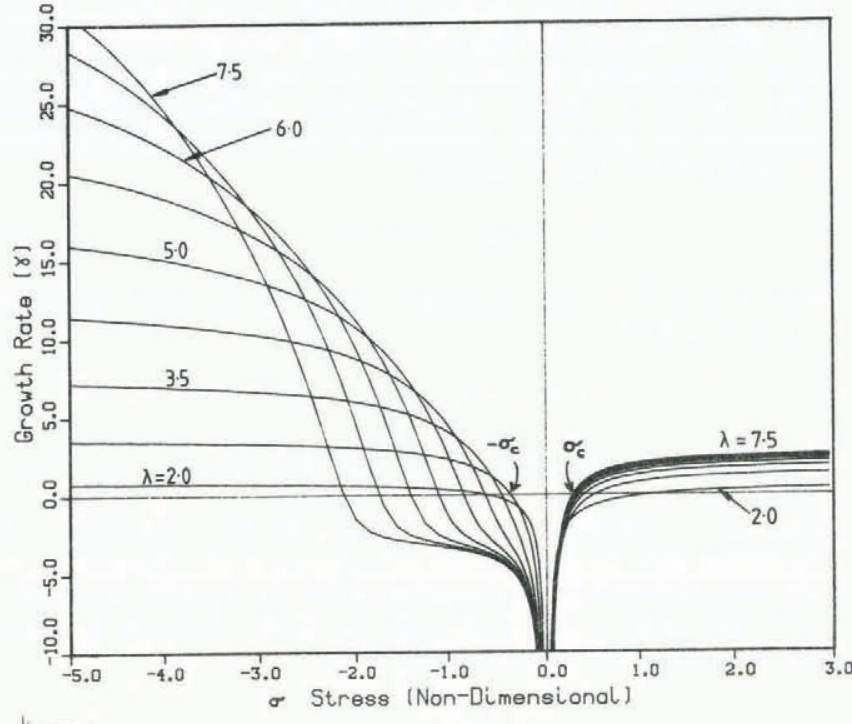

Fig. 3. Variation of non-dimensional growth rate $y$ with stress coefficient $\boldsymbol{\Sigma}$ for various values of non-dimensional wavelength $n . \quad\left(n=3\right.$ and $\left.\rho_{i} / \rho_{w}=0.75\right)$. The critical formation wavelength for a given value of $\sigma$ is that with the largest growth-rate and hence is given by the envelope to the above curves.

(i) For sufficiently small stress coefficients in the range $-\sigma_{c}<\sigma<\sigma_{e}$ the growth-rate is always negative irrespective of the wavelength. Thus in this regime the ice shelf is stable and all disturbances will be damped out.

(ii) In an extending flow region with $\sigma>\sigma_{e}$, positive growth-rates occur, but these are a monotonically increasing function of wavelength. Thus the wavelength with the largest growth-rate is theoretically infinite. This means that the ice shelf will tend to respond to perturbations by thinning or thickening uniformly over its entire length. Thus again in this regime one would not expect waves to grow.

(iii) For a sufficiently large compressive stress coefficient, so $\sigma<-\sigma_{c}$, the growth-rates are positive and have a maximum at a definite critical wavelength which depends on the value of $\sigma$. Thus in this regime one would expect waves of a definite finite wavelength to form. It is to be noted that even in this regime waves with a non-dimensional wavelength less than about 2 have negative growth-rates, so that this theory predicts that only waves whose initial wavelength is greater than about twice the local ice thickness can form under any circumstances. As shown in Figure 4, the critical formation wavelength

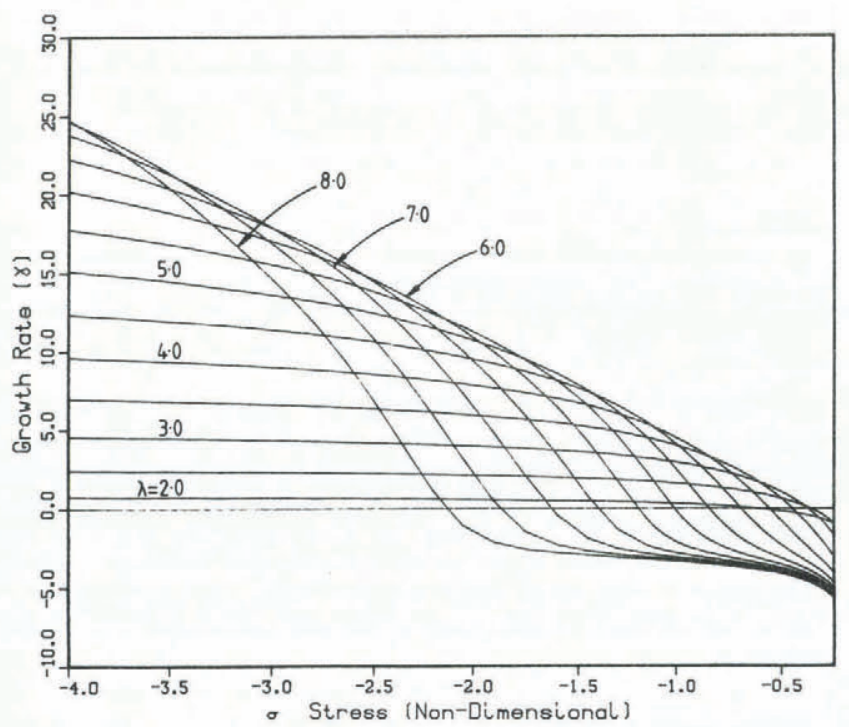

Fig. 4. Variation of non-dimensional growth rate $y$ with stress coefficient $\sigma$ (for negative $\sigma$ ) for various values of non-dimensional wavelength $\lambda\left(n=3\right.$ and $\left.\rho_{i} / \rho_{w}=0.75\right)$.
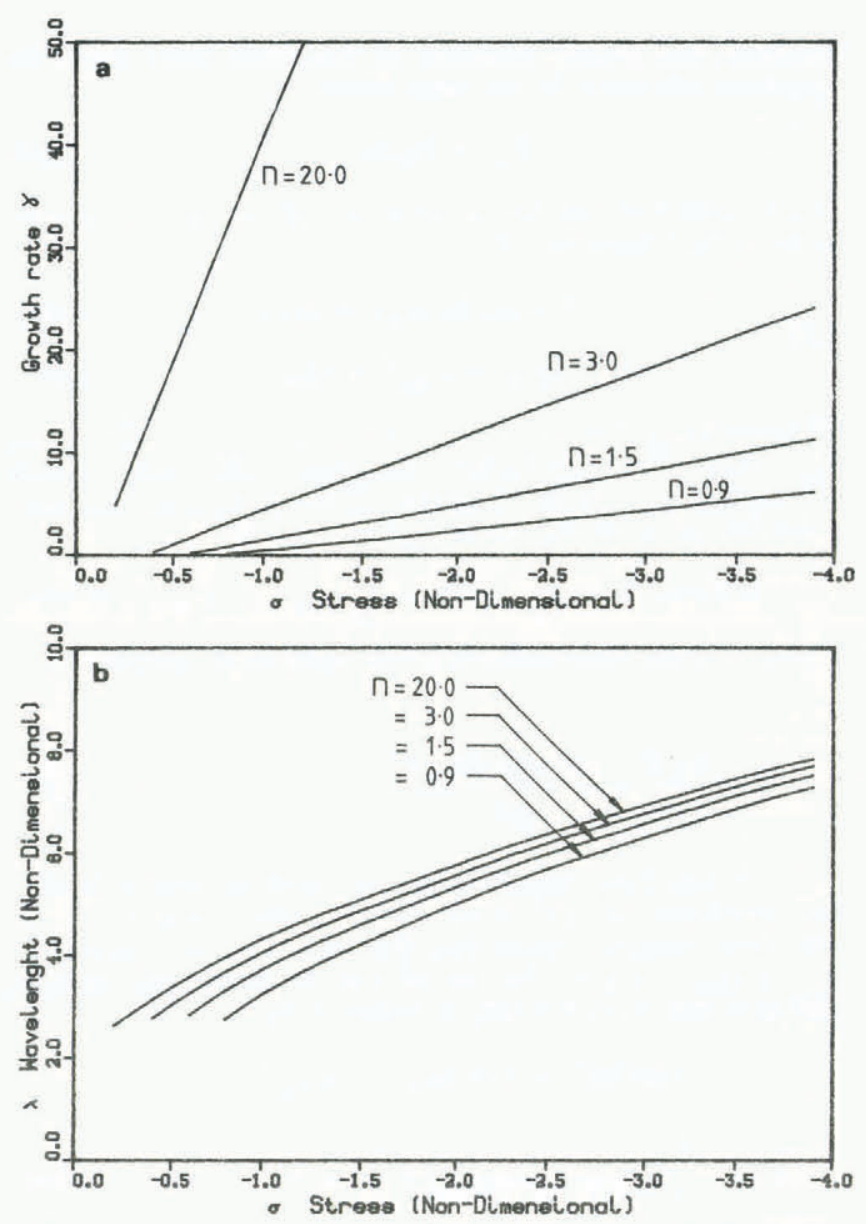

Fig. 5. a. Variation of critical formation wavelength with stress coefficient for various values of creep index $n$.

b. Variation of formation growth-rate with stress coefficient for various values of creep index $n$ $\left(\rho_{i} / \rho_{w}=0.75\right)$.

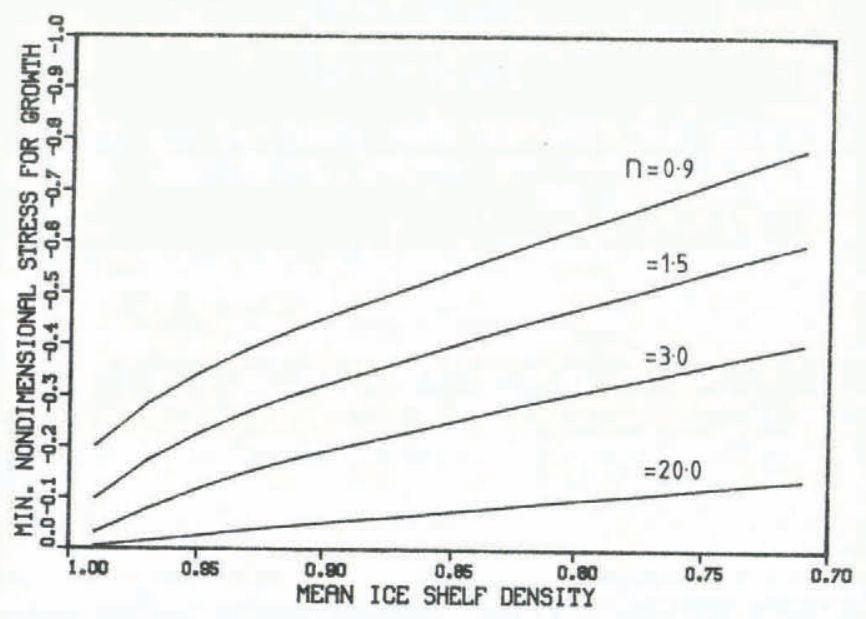

Fig. 6. Variation of critical stress coefficient $-\sigma_{C}$ at which waves can first form, with density ratio $\rho_{i} / \rho_{w}$ for various values of creep index $n$.

increases from around 2 when $\sigma=-\sigma_{c}=-0.3$ to 6 when $\sigma=-2.0$ and 8 when $\sigma=-4.0$. As shown in Figures 5 and 6 , the critical wavelength has only a slight dependence on $n$ but the value of the critical stress coefficient $\sigma_{c}$ decreases significantly as $n$ or the density ratio $\rho_{\mathrm{i}} / \rho_{\mathrm{w}}$ is increased.

Critical back pressures

The stress coefficient $\sigma$ is a measure of the deviatoric stress in the shelf. It is related to the "back pressure" $P$ by the formula

$$
\sigma=\frac{1}{2} \Delta \rho-P / \rho_{\mathrm{j}} g h
$$


which is obtained by eliminating the strain-rate $K$ between Equations (11) and (27). Thus for waves to form the back pressure must exceed the critical value $P_{c}$, where

$$
P_{c} / \rho_{\mathrm{i}} g h=\left(\frac{1}{2} \Delta \rho+\sigma_{c}\right) .
$$

Estimates of the values of the stress coefficient $\sigma$ in the Ross Ice Shelf can be made from the data on back pressure given by Thomas and MacAyeal (1982) and ice thickness by Bentley and others (1979). Values vary from 0.08 at the ice front, where the back pressure $P=0$ to around 0.00 at Crary Ice Rise or behind Roosevelt Island, where the retarding force $F=P h \sim 2 \times 10^{8} \mathrm{~N} \mathrm{~m}^{-1}$ and the ice thickness is $500-550 \mathrm{~m}$. These estimates of $\sigma$ are hence never compressive; they are however obtained by averaging data over a relatively large area. Here we require more localized information obtained from the neighbourhood of pressure ridges.For the two folds near Camp Michigan, Kehle (1964) estimated the value of the stress coefficient to be -1.9 , which is well into the region where waves can be expected to form (Figs 3 or 4). Similarly, preliminary estimates (see later) in the region where the Pram Point pressure ridges are forming on the McMurdo Ice Shelf give compressive stress coefficients of the order of -1.3 .

The above analysis is two-dimensional assuming the ice shelf is deforming under plane-strain conditions. However, as will be shown in the next section, the presence of lateral strain-rates can have a significant effect on the stability of the shelf. Further discussion of the comparison of the theory with available field data is hence delayed until after this extension of the theory has been presented.

\section{A note on the impossibility of wave propagation}

In the above analysis it has been shown that, if one looks for solutions which vary as $\exp (G t)$ with time and $\exp (i k x)$, then the growth-rate $G$ and wave number $k$ are simultaneously real. Similarly, solutions which are periodic in time, varying as $\exp (i \omega t)$, have real exponential variations with distance. It is hence impossible to find propagating wave solutions, varying as exp $i(\omega t-k x)$. This is not surprising in view of the quasi-static nature of the theory. As noted by Thompson (1979), it would be necessary to include the inertia terms in the equation of motion in order to study the possible development of progressive waves. This has not been attempted here.

\section{THE EFFECT OF LATERAL STRAINING}

\section{Zeroth-order solution}

Thomas (1973) generalized Weertman's steady-state solution to allow for lateral straining the in the $y$-direction. The zeroth-order strain-rates in Equation (6) are now replaced by

$$
\mathrm{e}_{x x}(0)=K, \mathrm{e}_{y y}^{(0)}=\alpha K, \mathrm{e}_{z z}{ }^{(0)}=-(1+\alpha) K
$$

where $\alpha=\mathrm{e}_{y y}{ }^{(0)} / \mathrm{e}_{x x}{ }^{(0)}$ is the ratio of lateral to longitudinal strain-rates. The previous theory can be modified to study the effect of lateral strain-rates on the growth of wave instabilities. The axes of the waves are still assumed to be normal to the $x$-principal strain-rate direction. The second strain-rate invariant is now

$$
\theta^{(0)}=K\left(1+\alpha+\alpha^{2}\right)^{\frac{1}{2}}
$$

and the zeroth-order viscosity is

$$
\mu_{0}=A\left(1+\alpha+\alpha^{2}\right)^{(1-n) / 2 n}|K|^{(1-n) / n}
$$

From the flow rule in Equation (1) the principal stress difference

$$
\left(\sigma_{x x}{ }^{(0)}-\sigma_{z z}{ }^{(0)}\right)=(2+\alpha) \mu_{0} K .
$$

Since $\sigma_{z z}{ }^{(0)}$ is still given by Equation (9) by equilibrium,

$$
\sigma_{x x}(0)=(2+\alpha) \mu_{0} K-\rho_{\mathrm{i}} g(h-z)
$$

Integrating through the ice thickness and introducing the back pressure $P$ and stress coefficient $\sigma$ as before, we obtain the modified form of Equation (42):

$$
\left(1+\frac{1}{2} \alpha\right) \sigma=\frac{1}{2} \Delta \rho-P / \rho_{\mathrm{i}} g h .
$$

The effect of lateral spreading is hence to introduce the $\left(1+\frac{1}{2} \alpha\right)$ term on the left-hand side. It is important to note that if $\alpha<-2, \sigma$ will have the opposite sign to the right-hand side of Equation (51). For example, at the seaward edge of an ice shelf, where $P=0$, it is possible to have a compressive strain-rate $(K<0)$ in the $x$-direction (normal to the ice front) provided the magnitude of the lateral extensional strain-rate in the $y$-direction is greater than $2|K|$

\section{Perturbation analysis}

The perturbation analysis proceeds in exactly the same way as before. Since the magnitudes of the zeroth-order strain-rates in the $x$ - and $z$-directions are no longer equal, the "effective viscosities" for superposed deformations in these directions are now different. The perturbed stress/strain-rate Equations (16) are replaced by

$$
\begin{aligned}
& \tilde{\sigma}_{x x}=-\tilde{p}+\eta_{x} \tilde{e}_{x x}, \\
& \tilde{\sigma}_{z z}=-\tilde{p}+\eta_{z} \tilde{e}_{z z}, \\
& \sigma_{x z}=\mu_{0} \tilde{e}_{x z}
\end{aligned}
$$

where

$$
\left.\begin{array}{l}
\eta_{x}=n_{0}\left(2+(1+n) \alpha+2 n \alpha^{2}\right) / 2 n\left(1+\alpha+\alpha^{2}\right), \\
\eta_{z}=\mu_{0}\left(2+(3-n) \alpha+(1+n) \alpha^{2}\right) / 2 n\left(1+\alpha+\alpha^{2}\right) .
\end{array}\right\}
$$

Both expressions reduce to $\mu_{0} / n$ when $\alpha=0$ and to $\mu_{0}$ when $n=1$.

Introducing a stream function and substituting in the equilibrium equations, we again arrive at the anisotropic biharmonic Equation (21) but with $n$ replaced by $n^{\prime}$, where

$$
n^{\prime}=\left(1+\alpha+\alpha^{2}\right) /\left(1+\alpha+\alpha^{2}(1+3 n) / 4\right) \text {. }
$$

The anisotropies introduced by the non-linear power law and the different background strain-rates are hence combined in the single parameter $n^{\prime}$. The derivation of the boundary conditions proceeds as before and again it is found that the only modification to Equations (26) and (28) is that $n$ replaced by $n^{\prime}$.

The variation of $n^{\prime}$ with $\alpha$ for various values of $n$, as given by Equation (54), is shown in Figure 7. As $\alpha$ increases from zero, the value of $\boldsymbol{n}$ decreases monotonically to $4 n /(3+n)$ when $\alpha=1$ and tends asymptotically to $4 n /(1+3 n)$ as $\alpha \rightarrow \infty$. The value of $n^{\prime}$ also decreases initially for negative values of $\alpha$, reducing to $4 n /(1+3 n)$ when $\alpha=-1$ and to 1 (for all $n$ ) when $\alpha=-2$; it then increases again slightly to $4 n /(1+3 n)$ as $\alpha \rightarrow-\infty$. In no case is the value of $n^{\prime}$ less than unity.

\section{Destabilizing effect of lateral straining}

The variation of the critical stress coefficient at which buckling occurs $\sigma_{c}$ with $\alpha$ can be determined by combining Figures 6 and 7. In general, the value of $\sigma_{c}$ increases with $|\alpha|$. However, the effect of lateral straining on the onset of buckling is best illustrated in Figure 8 where the value of the non-dimensional critical back pressure $P_{c} / \rho_{j} g h$, given by Equation (51), is plotted against $-\alpha$ for $n=3$ and for various density ratios. For $\alpha$ in the range 0 to -1 there is only a small decrease in the critical back pressure. This is because the reduction in $P_{c}$ caused by the $\left(1+\frac{1}{2} \alpha\right)$ term in Equation (51) is more or less balanced by the increase in the value of $\sigma_{c}$ caused by the increase in $|\alpha|$. However, the first effect is dominant when $\alpha<-1$ and $P_{c} / \rho_{i} g h$ decreases to $\frac{1}{2} \Delta \rho$ when $\alpha=-2$ and then becomes zero at some value between -2.3 and -2.5 depending on the density ratio. 


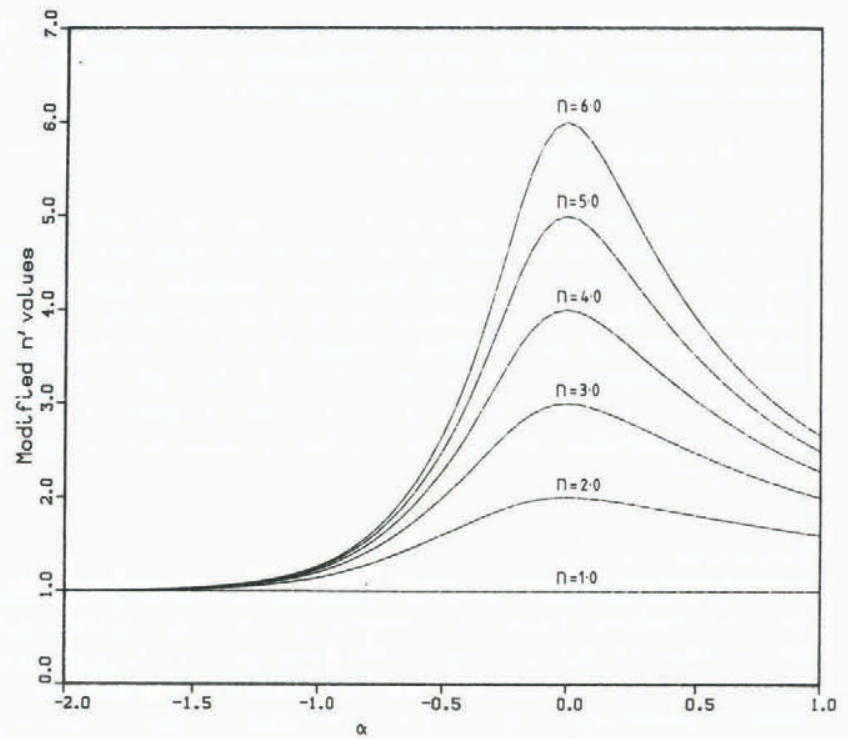

Fig. 7. Variation of "effective" creep index $n$ ' with lateral straining coefficient $\alpha=e_{y y}(0) / e_{x x}(0)$ for various values of creep index $n$.

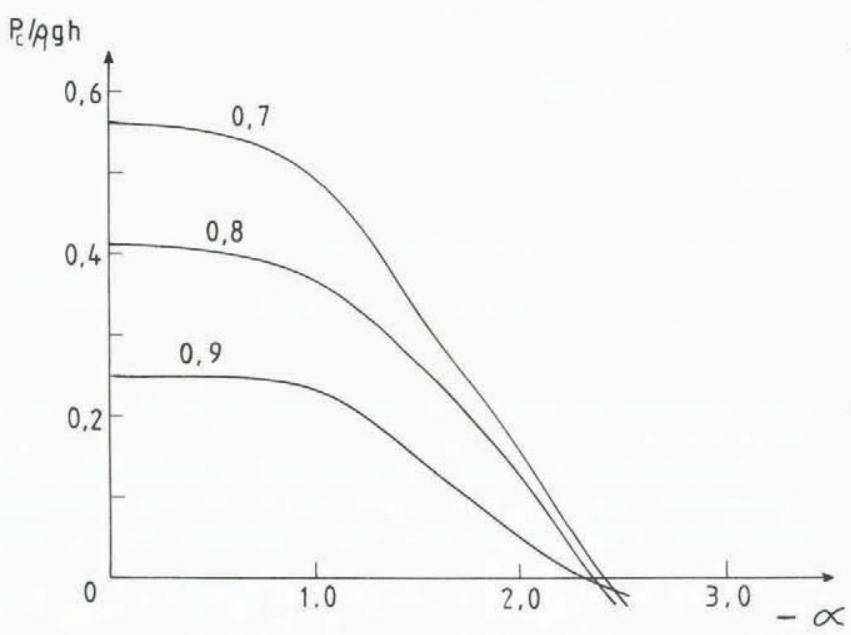

Fig. 8. Variation of critical back pressure $P_{c}$, at which waves can be expected to form, with the lateral straining coefficient $\propto$ for various density ratios $\boldsymbol{\rho}_{i} / \boldsymbol{p}_{w}$.

The presence of extensional lateral strain-rates $(\alpha<0)$ hence has a strong destabilizing effect and folds will form at a lower back pressure. In particular, on the seaward edge of an ice shelf where the back pressure is zero, the theory predicts that folds will still form provided the ratio of lateral extensional strain-rates to longitudinal compressive ones exceeds 2.3. This prediction hence supports, in general terms, Robin's (1979) hypothesis that these waves are caused by excessive lateral extensional strain-rates.

If both the $x$ and $y$ strain-rates are compressive $(\alpha>$ 0 ), then the value of the critical back pressure is increased. For example, if $\alpha=1$, so that the strain-rates are transversely isotropic in the plane of the shelf, the value of $P_{c} / \rho_{\mathrm{j}} g h$ is increased from 0.41 , for plane strain with $\alpha=0$, to 0.50 (for $\rho_{\mathrm{i}} / \rho_{\mathrm{w}}=0.8$ and $n=3$ ). Lateral compressive strain-rates hence have a stabilizing effect.

\section{Possible formation of oblique rollers}

Up to now it has been assumed that the axis of the train of rollers is at right-angles to a principal strain-rate direction. Intuitively this would seem to be necessary since the strain-rates achieve their maximum value in the principal directions. The limited amount of available field data also supports this conjecture. However, it proves a relatively simple matter to investigate the formation of waves aligned at an angle to the principal strain-rate directions.
Suppose as before that the $x$ - and $y$-axes are the principal strain-rate directions with strain-rates $K$ and $\alpha K(\alpha$ $\leqslant 1$ ), but that the train of folds forms with axes aligned perpendicular and parallel to the $x^{\prime}-$ and $y^{\prime}$-axes, which are inclined at an angle $\theta$ to the principal axes. The strain-rates referred to the primed axes are hence

$$
\begin{aligned}
& e_{x x}^{\prime}=K\left(\cos ^{2} \theta+\alpha \sin ^{2} \theta\right)=K^{\prime}, \\
& e_{y y}^{\prime}=K\left(\alpha \cos ^{2} \theta+\sin ^{2} \theta\right)=\alpha^{\prime} K^{\prime}, \\
& e_{x y}^{\prime}=-(1-\alpha) \cos \theta \sin \theta .
\end{aligned}
$$

Since $e^{\prime}{ }_{x z}=e^{\prime}{ }_{y z}=0$ and $e^{\prime}{ }_{x y}$ does not enter either the zeroth-order solution or the subsequent perturbation analysis, the above results apply equally well to the $x^{\prime}, y^{\prime}, z$ system of axes. The only change is that $\alpha$ and $K$ are replaced by $\alpha^{\prime}$ and $K^{\prime}$ as defined in Equations (55). The new strain-rate ratio $\alpha^{\prime}=e^{\prime}{ }_{y y} / e^{\prime}{ }_{x x}$ is expressed in terms of $\alpha$ and $\theta$ by

$$
\alpha^{\prime}(\theta)=\left(\alpha+\tan ^{2} \theta\right) /\left(1+\alpha \tan ^{2} \theta\right) .
$$

and the modified anisotropy parameter $n^{\prime}$ by Equation (54) but with $\alpha$ replaced by $\alpha^{\prime}$. The resulting critical compressive stress coefficient $\sigma_{c}(\theta)$ defined in terms of $K$ can then be found from Figures 6 and 7. Finally, the critical compressive-stress coefficient, referred to the principal $x-$ and $y$-axes is obtained from $\sigma_{c}^{\prime}$ by

$$
\sigma_{c}(\theta)=\sigma_{c}^{\prime}(\theta)\left(K / K^{\prime}(\theta)\right)^{\frac{1}{n}} .
$$

In order to deduce the orientation at which waves are likely to form, we look for the value of $\theta$ which gives the lowest value of $\sigma_{c}$. It is found that whilst $\sigma_{c}^{\prime}(\theta)$ can increase or decrease with $\theta$ depending on the value of $\alpha$, this effect is always outweighed by the fact that $\left(K / K^{\prime}(\theta)\right)^{1 / n}$ increases with $\theta$, so that in all cases $\sigma_{c}$ obtains its minimum at $\theta=$ 0 . This confirms our previous assumption that waves will develop normal to the maximum compressive strain-rate direction.

\section{THE EFFECT OF THROUGH-THICKNESS TEMPERA- TURE VARIATIONS}

So far the model used has neglected the variation of the effective viscosity through the thickness of the ice due to temperature and density gradients. If instead of being assumed constant the viscosity is regarded as a known function of the through-thickness variable $z$, then the Equation (21) for the perturbation stream function is modified to

$$
\begin{aligned}
& \Psi_{x x x x}+2\left(\frac{2}{n}-1\right) \psi_{, x x z z}+\psi_{, z z z z} \\
& +2\left(\mu_{0}^{\prime} / \mu_{0}\right)\left(\psi_{, z z z}+\left(\frac{2}{n}-1\right) \Psi_{x x z}\right) \\
& +\left(\mu_{0}^{\prime \prime} / \mu_{0}\right)\left(\psi_{, z z}-\psi_{x x}\right)=0
\end{aligned}
$$

where $\mu_{0}(z)$ is the zeroth-order viscosity. The derivation of this equation is given in the Appendix, where it is also shown how the four boundary conditions (24) to (26) are modified.

In view of the way in which $\mu_{0}$ and its derivatives enter Equations (58), it is convenient to assume an exponential variation of viscosity with depth, i.e.

$$
\mu_{0}(z)=\mu_{0}(0) \exp (s z / h)
$$

where $s$ is a dimensionless "decay constant" which is a measure of the specific viscosity gradient $\mu_{0} / \mu_{0}=s / h$. Its value can be deduced from estimated values of the viscosity on the top and bottom surfaces:

$$
s=\ln \left(\mu_{0}(h) / \mu_{0}(0)\right) \text {. }
$$


With this choice of viscosity function the governing Equation (58) and associated boundary conditions are still linear with constant coefficients and the techniques of classical stability analysis can still be employed.

The actual variations of viscosity with depth arise from the dependence of the flow-law parameter $B$ with temperature (cf. Equation (5)) given by the Arrhenius relationship

$$
B(T)=B_{0} \exp (Q / n R T)
$$

where $T$ is absolute temperature, $Q$ is the activation energy, and $R$ is the gas constant. Comparison between Equation (61) and the assumed exponential distribution for the McMurdo Ice Shelf in the area of the Pram Point pressure rollers shows good agreement as illustrated in Figure 9. Thomas and MacAyeal (1982) have suggested that the variation of viscosity with density is linear and can be modelled by the relation

$$
B(z)=B(T)(\rho(z)-\rho(h)) /\left(\rho_{\mathrm{i}}-\rho(h)\right)
$$

where $\rho(z)$ is the firn density at a height $z$. This can have a large effect on the variation of $B$ in a thin ice shelf, as at Pram Point, as shown in Figure 9. No attempt has been made to model the effect of density variations here however, as such a variation would mean that Equation (58) would no longer have constant coefficients.

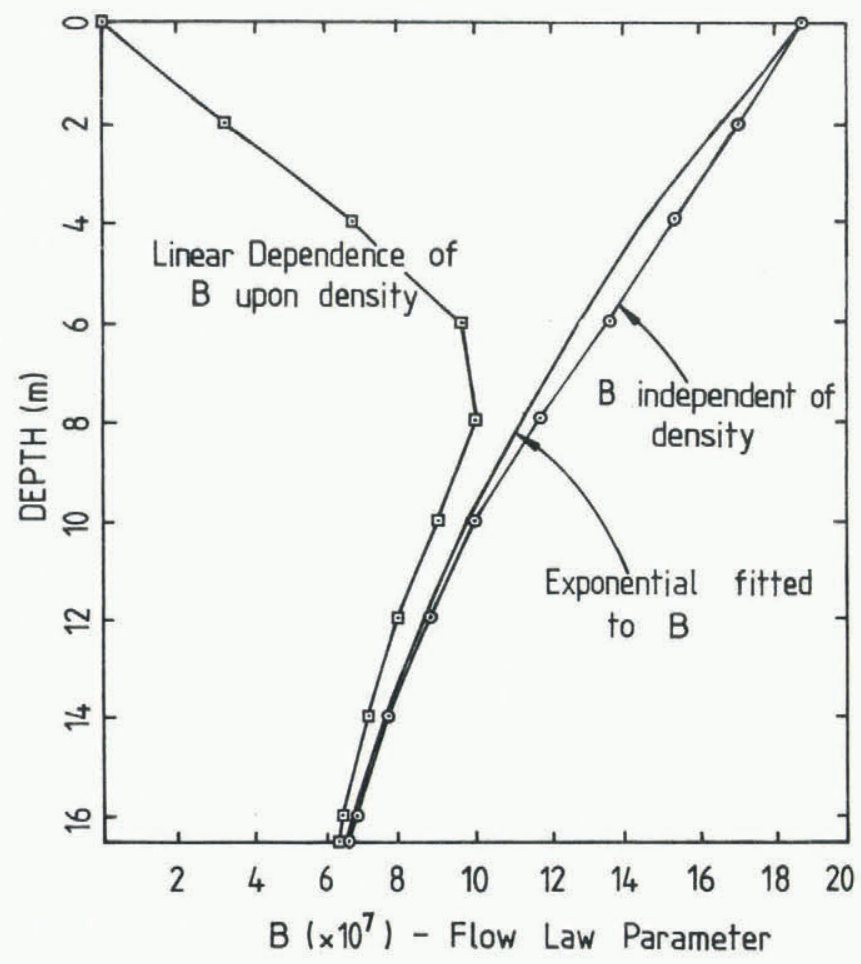

Fig. 9. Estimation of the variation of flow-law parameter $B$ $\left(\mathrm{Nm}^{-2} \mathrm{~s}^{1 / 3}\right)$ with depth for McMurdo Ice Shelf at Pram Point; (a) assuming exponential law (Equation (59)), (b) using the Arrhenius relationship (Equation (61)), and (c) allowing for density variations through Thomas and MacAyeal's equation (Equation (62)).

The variation of wavelength and growth-rate with stress coefficient was found to be very insensitive to variations in temperature gradient, provided the stress coefficient was taken to be $\bar{\sigma}$, the mean value averaged through the ice thickness. Since $\sigma$ is proportional to the viscosity, $\sigma$ too varies exponentially through the ice thickness, so that

$$
\bar{\sigma}=\sigma(h)\left(1-\mathrm{e}^{-s}\right) / s=\sigma(0)\left(\mathrm{e}^{s}-1\right) s .
$$

On the bottom surface of the ice shelf the temperature is $-1.5^{\circ} \mathrm{C}$. A top-surface temperature of $-20^{\circ} \mathrm{C}$ corresponds to a value of $s$ of around unity. The computed graphs of wavelength $\lambda$ and growth-rate $G / K$ against mean stress coefficient $\bar{\sigma}$ with $s=1$ were found to be indistinguishable from those in Figure 5 for $s=0$, although the value of $\sigma_{c}$ was found to increase (Fig. 10).

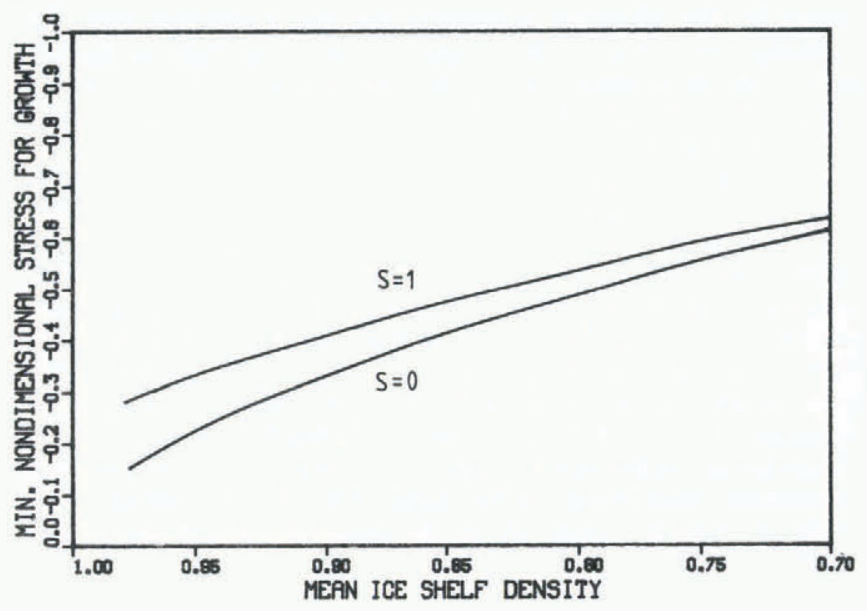

Fig. 10. Effect of exponential viscosity gradient on critical stress $-\sigma_{c}$ at which waves form $(\boldsymbol{n}=3)$.

\section{COMPARISON OF THEORETICAL PREDICTIONS WITH FIELD DATA}

\section{Summary of theoretical predictions}

The classical linear-stability analysis presented in the previous sections has led to the following predictions:

(a) The ice shelf will be unstable to small perturbations and will begin to buckle and form waves when the horizontal strain-rate $K$ is sufficiently compressive for the dimensionless stress coefficient $\sigma=2 \mu_{0} K / \rho_{i} g h$ to be less than some critical value $-\sigma_{c}$. The value of $\sigma_{c}$ decreases with increasing mean density ratio $\rho_{\mathrm{j}} / \rho_{\mathrm{w}}$ and creep-law index $n$ (Fig. 6), whilst the formation growth-rate and wavelength increases with the magnitude of the stress coefficient (Fig. 5). The instability criterion can alternatively be expressed in terms of a critical back pressure $P_{c}$ (Equation (43)).

(b) Local lateral extensional strain-rates have a destabilizing effect in that waves will form at lower values of compressive strain-rate or back pressure (Fig. 8). By contrast, lateral compressive strain-rates have a stabilizing influence. Waves will always form with their ridges at right-angles to the local compressive strain-rate direction.

(c) The through-thickness variation of viscosity resulting from temperature gradients can be adequately modelled by treating the viscosity as uniform and equal to its mean value. The variation in viscosity due to density variations has not been studied.

\section{Camp Michigan pressure rollers}

To date one of the most extensively studied sets of pressure rollers is those occurring in the Bay of Whales area of the Ross Ice Shelf near Camp Michigan. These have been described and analyzed by Zumberge and others (1960) and Kehle (1964). The strain-rate measurements reported by Kehle in Zumberge and others (1960) show that, when they form, these rollers have their ridges at right-angles to the direction of maximum compressive strain-rate. In many cases the lateral strain-rates are extensional, producing heavy crevassing at right-angles to the lines of the ridges. Kehle (1964) discussed two such rollers in detail, which have wavelength/thickness ratios of 4.4 and 5.8. Kehle also presented a theory for predicting these wavelengths based on Biot's (1965) model of folding of rock strata. In this theory, which is based on plate theory, the material is modelled by a linear visco-elastic material, although in the application to ice shelves Kehle put the elastic moduli to 
zero and so, in effect, used a linear viscous model $(n=1)$. $\mathrm{He}$ argued that this is a reasonable approximation to the real behaviour of ice provided the strain-rates do not change significantly over the distance of several wavelengths. However, the present more detailed analysis has shown that this assumption is false, since the non-Newtonian behaviour results in the effective viscosities for the perturbed flow in extension or compression being different to that in shear, which in turn means that the power-law index $n$ has a significant influence on the onset of buckling, particularly on the initial growth-rate.

Kehle estimated that the stress coefficients $\sigma$ in the region of the two rollers are, in the present notation, $-1.91 \pm 0.05$ and $-1.90 \pm 0.1$. With $n=3$, such a stress coefficient gives a non-dimensional wavelength of 5.7. The excellent agreement with the second fold is fortuitous. As emphasized by Kehle, the instability analysis only predicts the formation wavelength of the folds. Once formed, the wavelength of a fold will decrease and its amplitude increase as it moves forward through a region of compressive strain-rates. Thus, in order to compare the theoretical predictions with field data it is necessary to study a train of waves from the point at which the waves form.

\section{Pram Point pressure rollers}

The train of pressure rollers covering an area of 1.2 $\mathrm{km}$ by $1.8 \mathrm{~km}$ situated about $1.5 \mathrm{~km}$ north-east of Scott Base (Fig. 11) has been described by many writers including Stuart and Bull (1963), Hochstein (1967), and Holdsworth and Heine (1979). Recently, McCrae (1984) has presented a summary and analysis of glaciological measurements made in this area between 1960 and 1984.

The pressure rollers form in an area in which the ice is moving directly towards the land on Hut Point peninsula. In fact, McCrae (1984) observed that recent pole measurements indicate that the ice moves right up to the coastline, instead of turning towards the open sea as previously thought, so that the ice must all be lost by bottom melting. The rollers become visible at just over 1 km from Ross Island. Field measurements reported by Holdsworth and Heine (1979) revealed that the first detectable wave had a wavelength of $91 \pm 2 \mathrm{~m}$. From then on the wave-length decreased to $35 \mathrm{~m}$ whilst the amplitude increased from about $1 \mathrm{~m}$ to $3 \mathrm{~m}$.

Hochstein (1967) gave two surface-elevation profiles across the pressure ridges. Although these profiles were measured along lines (approximately) at right-angles to the ridges, their direction deviated by up to $40^{\circ}$ from the stream-line direction. This is because the rollers do not

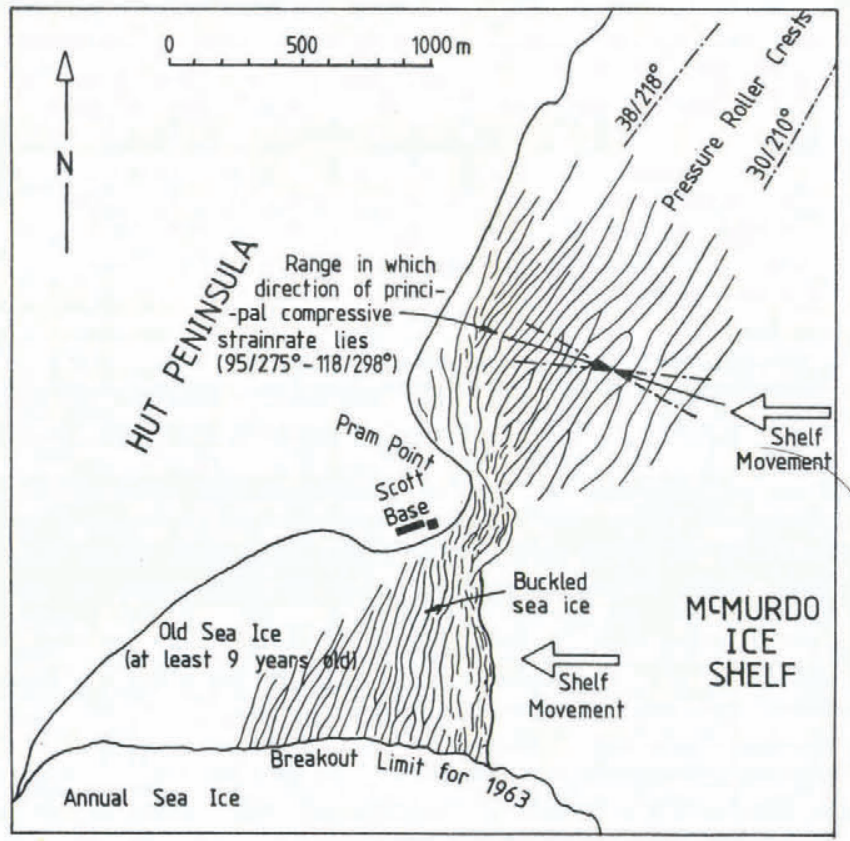

Fig. 11. Location of Pram Point pressure rollers on McMurdo Ice Shelf near Scott Base. remain parallel as they move across the shelf due to shearing in the horizontal plane. In an idealized shelf in which the deformation is plane strain with no cross shearing, the wavelength of the rollers should decrease linearly with distance. This can be seen as follows: assuming that, once formed, the waves remain embedded in the ice, their wavelength decreases at a rate equal to the compressive strain-rate, so

$$
\frac{\mathrm{d} \lambda}{\lambda}=-|K| \mathrm{d} t=\frac{\mathrm{d} u}{u}
$$

where $u$ is the local speed of the ice. If $u_{0}$ is the speed of the shelf at the point where a wave first forms, with wavelength $\lambda_{0}$ say, then this wave will have a wavelength given by

$$
\lambda=\lambda_{0} \exp (-|K| t)=\lambda_{0}\left(1-|K| x / u_{0}\right)
$$

when it has travelled a distance $x$ in time $t$. This epression is obtained by integrating Equation (64). Regression fits to the data given by Hochstein (1976) are shown in Figure 12 and show reasonable agreement with the linear law despite the deviation from the idealized plane-strain assumption.
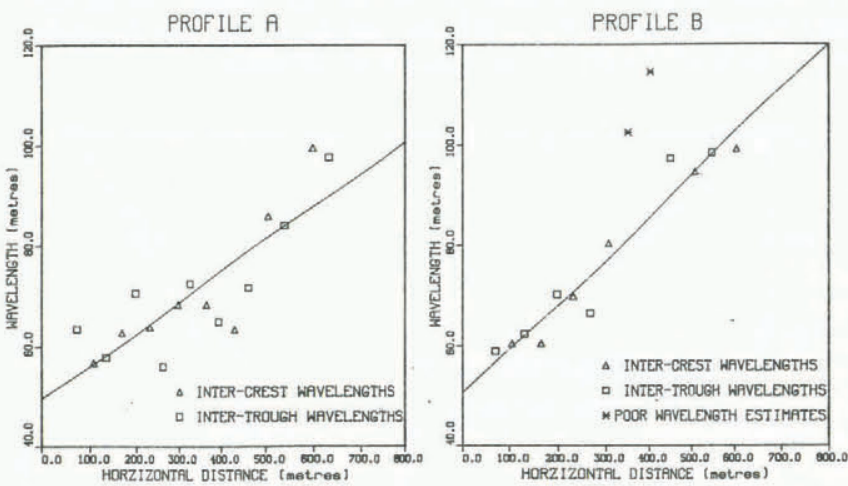

Fig. 12. Linear regression fits to wavelengths of profiles of Pram Point pressure rollers given by Hochstein (1967).

Clearly one of the major problems in comparing the predictions of the instability analysis with field data is in actually identifying the point at which the wave train forms. In an area, such as the McMurdo Ice Shelf where the strain-rates are becoming progressively more compressive as the ice approaches a land mass, it could be argued that the first wave should form at the point where the stress coefficient $\sigma$ is equal to $-\sigma_{c}(\sim-0.3)$, since from the theory this corresponds to the lowest value of compressive strain-rate at which a wave can form. However, as shown in Figure 5b, the growth-rate of such a wave is extremely small and will produce vertical velocities small compared with the local accumulation rate. The accumulation rate on this area of the shelf is about $0.4 \mathrm{~m} /$ year, whilst the compressive strain-rate is of the order of $0.06 /$ year (McCrae, 1984). With these figures it would require a wave amplitude of $7 \mathrm{~m}$ for the vertical velocity to equal the accumulation rate if the non-dimensional growth-rate $G / K=$ 1 , but only an amplitude of $0.7 \mathrm{~m}$ if $G / K=10$. We conclude from Figure $5 b$ therefore that it is unlikely that any forming wave could be detected in a region in which the magnitude of the stress coefficient is less than around unity.

The stress coefficient is given by $\sigma=-2 B|K|^{1 / n} / \rho_{\mathrm{j}} g h$ (cf. Equation (27)) and so is relatively insensitive to the value of the strain-rate $K$. However, its value does depend critically on accurate knowledge of the mean value of the flow-law parameter $B$, of the mean density, and of the ice thickness. McCrae (1984) has given several estimates of the mean value of $B$ for the Pram Point area, using either Thomas and MacAyeal's formula (Equation (62)) or values of $B(T)$ for pure ice given by Paterson (1981). When due account is taken of the variation of $B$ with density, as in Equation (62), and using the density and temperature 
profiles obtained by Hochstein and Risk (1967), estimates of $7.7 \pm 0.2 \times 10^{7} \mathrm{~N} \mathrm{~m}^{-2} \mathrm{~s} \frac{1}{3}$ for the mean value of $B$ were obtained from the above two sources. This figure, together with a strain-rate of $0.06 /$ year, mean density of $0.71 \times 10^{3}$ $\mathrm{kg} / \mathrm{m}^{3}$, and an estimated ice thickness of $20 \mathrm{~m}$, gives a value for $\sigma$ of -1.3 . The ice-thickness estimate is that given by Holdsworth and Heine (1979) for the area in which the rollers are forming and is calculated from the known freeboard of the shelf and the depth of the brine layer. It is compatible with the figure of $19 \pm 5 \mathrm{~m}$ given by Hochstein (1967) obtained by d.c. resistivity measurements. Hochstein also obtained a thickness value of $16.5 \mathrm{~m}$ from a drill site on the crest of the sixth roller. A stress coefficient of -1.3 corresponds to a non-dimensional wavelength of $4.2 \mathrm{~m}$ and an actual wavelength of $84 \mathrm{~m}$, which is hence in good agreement with the observed value of $91 \pm 2 \mathrm{~m}$. Thicknesses of $18 \mathrm{~m}$ or $22 \mathrm{~m}$ would give predicted wavelengths of 78 and $88 \mathrm{~m}$, respectively. (Note that since the non-dimensional wavelength varies approximately linearly with $\sigma$, the actual wavelength is rather less sensitive to uncertainties in the shelf thickness.) In view of the uncertainties in the values of the various quantities needed to calculate the stress coefficient, obtaining predicted wavelengths within $10 \%$ of observed values is held to be a reasonable validation of the theory. In this area the lateral strain-rate, which is extensional, is only $\sim 10 \%$ of the longitudinal value and hence has an insignificant effect on the stability of the shelf.

\section{DISCUSSIONS AND CONCLUSIONS}

The theoretical model used here to study the instability of floating ice shelves paralles that used by Smith (1977) to study the growth of folds in rock strata. The main difference between the two analyses is in the boundary conditions, which here describe the stress conditions on the upper free surface and lower sea-ice interface. In contrast, in Smith's analyses the buckling layer is confined between two semi-infinite layers with different viscosities. Smith found that the instabilities could sometimes be "fold-like" and sometimes be of "pinch-and-swell" type, as in a "boudinage", depending on the relative viscosities of the layers. In the ice-shelf problem, however, the analysis always predicts a "fold-like" instability, with the top and bottom waves being in phase but with a slightly larger amplitude on the bottom surface (typically by $5 \%$ ).

The appropriateness of Smith's analysis to the ice-shelf problem was recognized by Holdsworth and Heine (1979), who also discussed the relative merits of the two types of wave topographies. Field evidence of the "fold-like" nature of pressure rollers is needed to finally confirm the appropriateness of the analysis.

The theoretical model developed in this paper provides much potentially valuable information on the buckling instability of ice shelves. However, there is a major problem of interpretation in that it is not clear when a forming wave will have a sufficiently large growth-rate to be detectable. The first observable wave of the Pram Point train has an amplitude of $\sim 1 \mathrm{~m}$ with a theoretical growthrate of $0.35 \mathrm{~m} /$ year. The local surface accumulation is about $0.4 \mathrm{~m} /$ year which suggests that these two figures should be comparable before a developing wave will be observed. The predictions of the pressure-roller wavelengths, both at Camp Michigan and Pram Point, are encouraging and it is hoped that the availability of this theory will stimulate further, more detailed, field observations in these and other areas.

The basic theory has been successfully extended to cope with three-dimensional effects such as lateral strainh-rates and with the through-thickness viscosity variations caused by temperature gradients. The theory does not as yet include the influence of through-thickness density gradients, apart from when working out the mean effective viscosity. Such density variations may well be important in areas where the ice shelf is thin as at Pram Point. The present theory is purely mechanical and makes no attempt to include the effect of thermo-mechanical coupling. Williams and Hutter (1983) have shown that this coupling can produce instabilities in ice shelves.

\section{ACKNOWLEDGEMENTS}

The authors are grateful to the Antarctic Division of the New Zealand D.S.I.R. for financial support for this study, and to Professor M.P. Hochstein for many helpful discussions.

\section{REFERENCES}

Bentley, C.R., and others. 1979. Ice-thickness patterns and the dynamics of the Ross Ice Shelf, Antarctica, by C.R. Bentley, J.W. Clough, K.C. Jezek, and S. Shabtaie. Journal of Glaciology, Vol. 24, No. 90, p. 287-94.

Biot, M.A. 1965. Mechanics of incremental deformations. New York, John Wiley and Sons.

Fletcher, R.C. 1974. Wavelength selection in the folding of a single layer with power law rheology. American Journal of Science, Vol. 274, p. 1029-43.

Gould, L.M. 1935. The Ross shelf ice. Bulletin of the Geological Society of America, Vol. 46, p. 1367-83.

Hochstein, M.P. 1967. Pressure ridges of the McMurdo Ice Shelf near Scott Base, Antarctica. New Zealand Journal of Geology and Geophysics, Vol. 10, No. 4, p. 1165-68.

Hochstein, M.P., and Risk, G.F. 1967. Geophysical measurements on the McMurdo Ice Shelf. Antarctica during 1965-66. Wellington, New Zealand, Department of Scientific and Industrial Research. Geophysics Division. (Report No. 47.)

Holdsworth, G., and Heine, A.J. 1979. Undulations on the McMurdo Ice Shelf near Scott Base, Antarctica. New Zealand Antarctic Record, Vol. 2, No. 2, p. 16-22.

Hughes, T. 1983. On the disintegration of ice shelves: the role of fracture. Journal of Glaciology, Vol. 29, No. 101, p. 98-117.

Kehle, R.O. 1964. Deformation of the Ross Ice Shelf, Antarctica. Geological Society of America. Bulletin, Vol. 75 , No. 4 , p. $259-86$.

McCrae, I.R. 1984. A summary and analysis of glaciological measurements made between 1960 and 1984 on the Scott Base pressure rollers. Auckland, New Zealand, University of Auckland. School of Engineering. (Report No. 360.)

Mawson, D., Sir. 1915. The home of the blizzard. London, William Heinemann.

Neurath, C., and Smith, R.B. 1982. The effect of material properties on growth rates of folding and boudinage: experiments with wax models. Journal of Structural Geology, Vol. 4, No. 2, p. 215-29.

Odqvist, F.K.G. 1966. Mathematical theory of creep and creep rupture. Oxford, Clarendon Press.

Paterson, W.S.B. 1981. The physics of glaciers. Second edition. Oxford, etc., Pergamon Press. (Pergamon International Library.)

Robin, G. de Q. 1979. Formation, flow, and disintegration of ice shelves. Journal of Glaciology, Vol. 24, No. 90, p. 259-71.

Smith, R.B. 1975. Unified theory of the onset of folding, boudinage and mullion structure. Geological Society of America. Bulletin, Vol. 86, p. 1601-09.

Smith, R.B. 1977. Formation of folds, boudinage, and mullions in non-Newtonian materials. Geological Society of America. Bulletin, Vol. 88, p. 312-20.

Smith, R.B. 1979. The folding of a strongly non-Newtonian layer. American Journal of Science, Vol. 279, p. 272-87.

Stuart, A.W., and Bull, C.B.[B.] 1963. Glaciological observations on the Ross Ice Shelf near Scott Base, Antarctica. Journal of Glaciology, Vol. 4, No. 34, p. 399-414.

Swithinbank, C.W.M. 1957. Glaciology. I. The regime of the ice shelf at Maudheim as shown by stake measurements. Norwegian-British-Swedish Antarctic Expedition, 1949-52. Scientific Results, Vol. 3 B, p. 41-75.

Thomas, R.H. 1973. The creep of ice shelves: theory. Journal of Glaciology, Vol. 12, No. 64, p. 45-53.

Thomas, R.H. 1979. Ice shelves: a review. Journal of Glaciology, Vol. 24, No. 90, p. 273-86.

Thomas, R.H., and MacAyeal, D.R. 1982. Derived characteristics of the Ross Ice Shelf, Antarctica. Journal of Glaciology, Vol. 28, No. 100, p. 397-412. 
Thompson, D.E. 1979. Stability of glaciers and ice sheets against flow perturbations. Journal of Glaciology, Vol. 24, No. 90 , p. $427-41$.

Weertman, J. 1957. Deformation of floating ice shelves. Journal of Glaciology, Vol. 3, No. 21, p. 38-42.

Williams, F.M., and Hutter, K. 1983. Thermal response of unconfined ice shelves to climatic conditions. Acta Mechanica, Vol. 48, No. 3, p. 131-46.

\section{APPENDIX}

\section{Effect of viscosity variations}

The development of the theory presented in the text must be modified when the viscosity varies through the ice thickness. We assume that the viscosity in the base solution $\mu_{0}$ is a known function of $z$. The zeroth-order background stresses are still given by Equation (9) and the perturbation stress/strain-rate relations are of the form of Equation (16). However, some extra terms arise when these stresses are substituted in the equilibrium equations, and Equations (20) giving the pressure gradients are modified to

$$
\left.\begin{array}{rl}
\tilde{p}, x & =\mu_{0}\left[\frac{1}{n}-\frac{1}{2}\right] \psi, x x z+\frac{1}{2} \mu_{0} \psi, z z z+ \\
& +\frac{1}{2} \mu_{0}{ }^{\prime}\left(\psi_{y_{z z}}-\psi, x x\right) \\
\tilde{p},_{z} & =-\mu_{0}\left(\frac{1}{n}-\frac{1}{2}\right) \psi_{x z z}-\frac{1}{2} \mu_{0} \psi_{x x x}-\frac{1}{2} \mu_{0}^{\prime} \psi_{x z}
\end{array}\right\}
$$

where $\mu_{0}^{\prime} \equiv \mathrm{d} \mu_{0} / \mathrm{d} z$.

Eliminating $\tilde{p}$ between these relations gives the modified equation for the stream function

$\psi \cdot x x x x+2\left[\frac{2}{n}-1\right] \psi_{\cdot} x x z z+\psi_{z z z z}+$

$+2\left(\mu_{0}^{\prime} / \mu_{0}\right)\left(\psi, z z z+\left[\frac{2}{n}-1\right] \Psi_{x x z}\right)+$

$+\left(\mu_{0} " / \mu_{0}\right)(\psi, z z-\psi, x x)=0$.

Two out of the four boundary conditions also have to be modified. The perturbation stresses on the top surface are still given by Equations (24) and (25), with $\mu_{0}$ being evaluated at $z=h$ but, after being expressed in terms of the stream function and pressure, the elimination of $\tilde{p}$, from Equations (A.1) yields an extra term involving the
Wright, C.S., and Priestley, R.E. 1922. Glaciology, British (Terra Nova) Antarctic Expedition 1910-1913. London, Harrison and Sons.

Zumberge, J.H., and others. 1960. Deformation of the Ross Ice Shelf near the Bay of Whales, Antarctica, by J.H. Zumberge, M. Giovinetto, R. Kehle, and J. Reid. I.G.Y. Glaciological Report Series (New York), No. 3.

viscosity gradient $z=h$. In consequence the boundary condition in Equation (26) is replaced by

$$
\begin{aligned}
& \left((1 / h \sigma(h))-\mu_{0}^{\prime}(h) / \mu_{0}(h)\right)\left(\Psi_{z z}-\Psi_{x x}\right)+ \\
+ & (1-4 / n) \Psi_{x x z}-\Psi_{z z z}=0
\end{aligned}
$$

where $\sigma(h)$ is the value of the stress coefficient, defined by Equation (27), but evaluated on the upper surface of the shelf. Similarly, the boundary condition in Equation (28) on the lower surface becomes

$$
\begin{gathered}
-\left(\left(\Delta \rho / h \sigma(0)(1-\Delta \rho)+\mu_{0}^{\prime}(0) / \mu_{0}(0)\right)\left(\Psi_{z z}-\Psi_{x x}\right)+\right. \\
+(1-4 / n) \Psi_{x x z}-\Psi_{, z z z}=0 .
\end{gathered}
$$

The two kinematic boundary conditions in Equation (33) are unaltered.

When the viscosity variation is taken to be exponential

$$
\mu_{0}(z)=\mu_{0}(0) \exp (s z / h)
$$

the ratio $\mu_{0}^{\prime} / \mu_{0}=s / h$ is constant through the ice thickness whilst $\sigma(h) / \sigma(0)=\exp (s)$.

Wave solutions of Equation (A2) of the form $\exp (i k x) \exp (v k z)$ exist, provided $v$ is a root of the quartic equation

$v^{4}=2 \delta v^{3}+\left(\delta^{2}-2 \omega\right) v^{2}-2 \delta \omega v+\left(1+\delta^{2}\right)=0$

where $\omega=(2-n$ and $\delta=s / k h$. This equation reduces to Equation (35) when $s=0$. Denoting the four roots of this equation by $v_{j}$, the first two rows of the fundamental matrix $B$ in Equation (40) are still as in Equation (39) but the last two rows are modified to

$$
\left(\left(1-\sigma(h) h k\left(\delta+v_{j}\right)\right)\left(1+v_{j}^{2}\right)+4 \sigma(h) h k v_{j} / n\right) \exp \left(h k v_{j}\right)
$$

and

$$
\begin{aligned}
& \left(-\left((\Delta \rho /(1-\Delta \rho)) \exp (h k \delta)+\sigma(h) h k\left(\delta+v_{j}\right)\right)\left(1+v_{j}^{2}\right)+\right. \\
& \left.\quad+4 \sigma(h) h k v_{j} / n\right) .
\end{aligned}
$$

